\title{
Padrão de celularidade nas vias aéreas superiores de lactentes com bronquiolite aguda: neutrófilos ou eosinófilos?
}

\author{
Upper airway cellular pattern in infants with acute bronchiolitis: \\ neutrophils or eosinophils? \\ Paulo M.C. Pitrez ${ }^{1}$, Leonardo A. Pinto ${ }^{2}$, Denise C. Machado ${ }^{3}$, \\ Maria T. Tsukazan ${ }^{4}$, Marcus H. Jones ${ }^{5}$, Renato T. Stein ${ }^{5}$
}

\section{Resumo}

Objetivo: O objetivo deste estudoé analisar o exame citológico do aspirado nasofaríngeo de lactentes com bronquiolite aguda, especificamente em relação à presença de neutrófilos e eosinófilos.

Métodos: Foram recrutados lactentes hospitalizados com diagnóstico de bronquiolite aguda, no Hospital São Lucas da PUCRS, no período entre maio e julho de 2002. O aspirado nasofaríngeo foi coletado nas primeiras 48 horas de internação hospitalar. O exame citológico diferencial foi realizado com coloração de May Grunwald Giemsa. Foram realizadas também contagem total de células e viabilidade celular nas amostras estudadas.

Resultados: Foram selecionados 38 lactentes com bronquiolite aguda. A idade mediana foi de 2,2 meses (interquartil: 1,2-3,5), sendo 21 pacientes do sexo masculino. O exame citológico diferencial demonstrou um predomínio absoluto de neutrófilos, com mediana de 95\% (interquartil: 94-97). Não foi detectada a presença de eosinófilos nas amostras estudadas.

Conclusões: $\mathrm{O}$ aspirado nasofaríngeo de lactentes hospitalizados com bronquiolite aguda apresenta um predomínio absoluto de neutrófilos. Não foram encontrados eosinófilos nessas amostras. Esses achados demonstram que lactentes com bronquiolite aguda apresentam uma resposta inflamatória neutrofílica, nas vias aéreas, aos vírus respiratórios, distinta daquela eosinofílica, encontrada em quadros de asma.

J Pediatr (Rio J) 2003;79(5):443-8: Bronquiolite aguda, inflamação, neutrófilo, eosinófilo.

\begin{abstract}
Objective: To analyze the cellular pattern of nasopharyngeal secretions in infants with acute bronchiolitis $(\mathrm{AB})$, focusing on the presence or absence of neutrophils and eosinophils.

Methods: Hospitalized children with $\mathrm{AB}$ admitted to Hospital São Lucas, Porto Alegre, Brazil, between May and July 2002 were recruited. Nasopharyngeal aspirates were collected during the first 48 hours after admission. Slides were stained with May Grunwald and Giemsa. Total cell count and cellular viability were obtained in all samples.

Results: Thirty-eight infants with $\mathrm{AB}$ were enrolled. The mean age was 2.2 months (interquartile range: $1.2-3.5$ ), and 21 subjects were male. Neutrophils were the predominant cells in the nasopharyngeal aspirates (median 95\%, interquartile: 94-97). No eosinophils were found in the samples studied.

Conclusion: Our results suggest that eosinophils do not play a significant role in the pathophysiogenesis of $\mathrm{AB}$. Infants with $\mathrm{AB}$ present a specific inflammatory response to viral infections, which is distinct from the immune response observed in asthma.
\end{abstract}

J Pediatr (Rio J) 2003;79(5):443-8: Acute bronchiolitis, inflammation, neutrophil, eosinophil.

1. Médico da Equipe de Pneumologia Pediátrica do Hospital São Lucas da PUCRS. Doutor em Pneumologia (UFRGS).

2. Residente de Pneumologia Pediátrica do Hospital São Lucas da PUCRS.

3. Professora do Dep. de Medicina Interna da PUCRS, Doutora em Imunologia Molecular (University of Sheffield).

4. Bolsista de iniciação científica (FAPERGS).

5. Professor do Departamento de Pediatria da PUCRS. Doutor em Pneumologia (UFRGS).

Artigo submetido em 20.01.03, aceito em 28.05.03. 


\section{Introdução}

A bronquiolite aguda (BA) é a causa mais comum de doença obstrutiva das vias aéreas inferiores nos primeiros dois anos de vida. Em países desenvolvidos, aproximadamente $1 \%$ dos pacientes necessitam admissão hospitalar. Apesar da mortalidade ser baixa, a morbidade desta doença é significativa em lactentes previamente saudáveis ${ }^{1}$. Os fatores que determinam a gravidade do episódio agudo e a recorrência dos sintomas de sibilância ainda não são bem conhecidos.

A proteína catiônica eosinofílica (PCE), uma proteína presente nos grânulos de eosinófilos e que apresenta ação citotóxica na via aérea, está aumentada nas secreções de pacientes com BA e sibilância nos primeiros dois anos de vida $^{2-4}$. Esses estudos têm sugerido que a resposta imune na BA seja predominantemente desencadeada por eosinófilos, que é uma célula com papel central na fisiopatogenia de asma de característica alérgica. Entretanto, estudos que analisaram o exame citológico de pacientes com BA demonstraram que a celularidade diferencial em secreção nasal e lavado broncoalveolar apresentam um predomínio absoluto de neutrófilos ${ }^{5-8}$. Portanto, o tipo de resposta inflamatória celular nas vias aéreas que caracteriza esta doença permanece ainda pouco esclarecido.

Vários fatores ambientais e genéticos parecem interferir no desenvolvimento de doença respiratória alérgica nos primeiros anos de vida, existindo inclusive uma diferença na prevalência de asma de origem atópica entre países desenvolvidos e países em desenvolvimento ${ }^{9-10}$. Não existem relatos de estudos analisando a resposta celular nas vias aéreas de lactentes com BA em países em desenvolvimento. O conhecimento sobre o tipo de resposta celular no aparelho respiratório desses pacientes é essencial para o melhor entendimento da fisiopatogenia da BA, podendo auxiliar no desenvolvimento de novas modalidades diagnósticas e terapêuticas. Antes de se desenvolver estudos mais específicos para elucidar esta questão, é necessário que se conheça o exame citológico de lactentes com BA de uma amostra de uma população de um país em desenvolvimento. A hipótese do presente estudo é de que o papel dos eosinófilos em lactentes com BA nãoé importante. O objetivo deste estudo é analisar o exame citológico diferencial do aspirado nasofaríngeo de pacientes com BA, especificamente em relação à presença de neutrófilos e eosinófilos.

\section{Métodos}

\section{Seleção da amostra}

Foram selecionadas crianças com menos de dois anos de idade, com primeiro episódio de sibilância, com sinais e sintomas de infecção viral aguda (coriza e tosse nos sete dias anteriores), que necessitaram de hospitalização no Hospital São Lucas da PUCRS, devido à dificuldade respiratória ou não aceitação da via oral, no período entre maio e julho de 2002. Foram excluídos todos os casos com diagnósticos prévios de fibrose cística, cardiopatia congênita, imunodeficiências ou doença pulmonar crônica da prematuridade. Também foram excluídos todos os pacientes que estavam em uso de corticóide tópico ou sistêmico, ou cuja amostra da coleta de secreção nasofaríngea fosse insuficiente. Hipoxemia foi considerada quando a saturação (mensurada por oximetria de pulso na admissão do paciente) fosse menor do que $96 \%$. Para estes pacientes, era iniciada oxigenoterapia.

\section{Coleta e processamento da amostra}

$\mathrm{O}$ aspirado nasofaríngeo (ANF) foi coletado com uma sonda de aspiração número 6, introduzida na nasofaringe, conectada a um sistema de aspiração e frasco de coleta. Todas as coletas foram realizadas nas primeiras 48 horas da admissão hospitalar. A sonda, ao final da aspiração, era lavada com 1,5 $\mathrm{ml}$ de soro fisiológico.

Foi separado $1 \mathrm{ml}$ do ANF para detecção de vírus sincicial respiratório (VSR), adenovírus, influenza e parainfluenza, através do método de imunofluorescência direta.

O material restante foi pesado e centrifugado $(2.000$ rpm por 2 minutos). O precipitado da amostra foi suspenso em $1 \mathrm{ml}$ de solução salina tamponada (PBS) e 40ml desta suspensão foi utilizada para preparação de lâminas para citologia diferencial, em citocentrífuga (FANEM, São Paulo, Brasil, Mod. 218), a $500 \mathrm{rpm}$ por 5 minutos. Duas lâminas para cada paciente foram fixadas com álcool metílico e coradas com May Grunwald Giemsa. As células foram analisadas de acordo com sua morfologia característica, sempre pelo mesmo investigador (P.M.C.P.). Os tipos de células observadas ao microscópio óptico foram expressas em percentagem, após contagem de 200 células por lâmina. Foi escolhida para contagem a lâmina com melhor qualidade de coloração e distribuição de células. Foi determinada a contagem de 200 células por lâmina, devido à não tão freqüente abundância de células no ANF, como aquela encontrada em escarro ou lavado broncoalveolar.

Contagem total de células (CTC) e viabilidade celular foram realizadas em todas as amostras, através do método de exclusão com azul de tripan, em câmara de Neubauer (Boeco, Germany).

\section{Análise estatística}

Para análise das variáveis do estudo, foram utilizados os testes $t$ e de Mann-Whitney, para um nível de significância de 0,05 .

\section{Ética}

Este estudo foi aprovado pela comissão de ética em pesquisa do Hospital São Lucas da PUCRS. Todos os responsáveis pelos pacientes que participaram do estudo assinaram termo de consentimento informado. 


\section{Resultados}

Foram recrutados 45 lactentes hospitalizados com BA. Sete pacientes foram excluídos, devido à quantidade da amostra para processamento da análise celular ser insuficiente. Trinta e oito lactentes foram incluídos no estudo. Os dados demográficos e clínicos estão resumidos na Tabela 1. Vírus respiratórios foram detectados em 29/38 (76\%) amostras de ANF. O VSR foi detectado em todas as amostras. Houve identificação de adenovírus (2/38) e influenza (1/38), todos associados à infecção por VSR. A maioria dos pacientes necessitou de oxigenoterapia (28/38 casos) e 5 pacientes necessitaram de ventilação mecânica. Os 10 lactentes que não necessitaram de oxigenoterapia foram hospitalizados devido à não aceitação da via oral em lactentes jovens (lactentes jovens).

A mediana da contagem CTC das amostras foi de 1,6 x $10^{6}$ céls/ml (interquartil: $0,5-2,6$ ), com uma viabilidade de 95\% (interquartil: 91-97). Houve um predomínio absoluto de neutrófilos no ANF dos pacientes estudados. Não foi encontrado nenhum eosinófilo nessas amostras. O exame citológico do ANF demonstrou uma mediana de 95\% de neutrófilos (interquartil: 94-97), 3\% de macrófagos (interquartil: $3-4$ ), $1 \%$ de linfócitos e $0 \%$ de células epiteliais ou eosinófilos. Os achados do exame citológico diferencial do ANF dos pacientes estudados são apresentados na Figura 1. A CTC e o exame citológico diferencial no ANF não demonstraram nenhuma diferença significativa, quando foram analisados em relação à necessidade de oxigenoterapia (Tabela 2). Além disso, não foi encontrada nenhuma diferença significativa quando estas variáveis foram analisadas em relação à necessidade de ventilação mecânica, tabagismo domiciliar ou positividade de VSR no ANF.

\section{Discussão}

No presente estudo, foi encontrado um predomínio absoluto de neutrófilos no aspirado nasofaríngeo de lactentes com BA. Além disso, não foi encontrada a presença de eosinófilos em nenhuma amostra de secreção nasal. Esses resultados confirmam os achados de estudos anteriores ${ }^{5,6,8}$, sugerindo que os neutrófilos sejam as principais células envolvidas na resposta inflamatória aguda nas vias aéreas de lactentes com BA. Além disso, nossos resultados reforçam o questionamento sobre a existência de um papel significativo do eosinófilo na fisiopatogenia da BA.

Não foi encontrada nenhuma relação entre a contagem total de células ou o número de neutrófilos no ANF e a gravidade do episódio de BA (necessidade de oxigenoterapia ou ventilação mecânica). Apesar da amostra de pacientes ser pequena para analisar fatores de risco de gravidade neste estudo, é provável que a relação destas variáveis com a gravidade do quadro de BA não exista realmente. A inclusão de um grupo controle em estudos futuros, como lactentes com infecções de vias aéreas superiores, poderia esclarecer melhor esta questão.

Tabela 1 - Características demográficas dos pacientes estudados

\begin{tabular}{lc}
\hline & Pacientes $(\mathbf{n}=\mathbf{3 8})$ \\
\hline Idade (meses), mediana & $2,2(1,2-3,5)$ \\
Sexo, masculino (\%) & $21(55)$ \\
História familiar de atopia (\%) & $27(71)$ \\
VSR positivo (\%) & $29(76)$ \\
Oxigenoterapia (\%) & $28(74)$ \\
Ventilação mecânica (\%) & $5(13)$ \\
\hline
\end{tabular}

Tabela 2 - Comparação entre a contagem total de células (CTC) e o exame citológico diferencial do aspirado nasofaríngeo de lactentes com bronquiolite aguda em relação à presença de hipoxemia

\begin{tabular}{lccc}
\hline & $\begin{array}{c}\text { Com hipoxemia } \\
\mathbf{n = 2 8}\end{array}$ & $\begin{array}{c}\text { Sem hipoxemia } \\
\mathbf{n = 1 0}\end{array}$ & Valor do p \\
\hline CTC (céls x 10\%/ml) & $1,82(0,86-3,0)$ & $1,0(0,5-2,2)$ & NS* \\
Percentagem de neutrófilos $(\%)$ & $95(93-97)$ & $96(94-97)$ & NS \\
\hline
\end{tabular}

* NS: não significativo. 


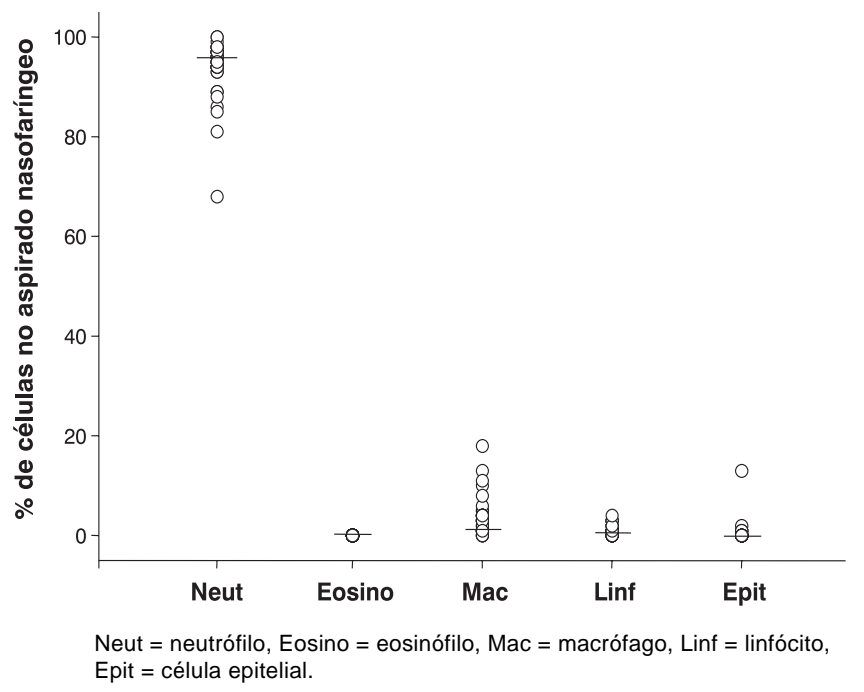

Figura 1 - Característica do exame citológico diferencial do aspirado nasofaríngeo de lactentes com bronquiolite aguda

Foram utilizadas, nesse estudo, amostras de secreção nasal, para análise da resposta celular de lactentes com BA. As amostras de ANF foram adequadamente coletadas e processadas, considerando-se os valores encontrados na CTC e na viabilidade celular. O ANF poderia não representar o tipo de resposta inflamatória encontrada nas vias aéreas inferiores. Entretanto, em pacientes com BA, a secreção nasal tem sido utilizada como uma forma de análise da resposta imune das vias aéreas inferiores. A secreção nasofaríngea obtida através do ANF ou de lavado nasal é fácil e rápida de coletar. Vários estudos descritos na literatura têm utilizado a secreção nasal como método diagnóstico de inflamação do aparelho respiratório ${ }^{11-15}$. Em lactentes com sibilância, este método tem sido freqüentemente empregado no estudo da resposta imune ${ }^{2,5,6,15}$. A correlação dos achados da análise da resposta inflamatória entre vias aéreas superiores e inferiores ainda não está clara. Porém existem alguns estudos que demonstraram haver uma boa correlação entre esses dois locais. Joshi et al. ${ }^{16}$, realizando ANF e aspirado traqueal simultâneos e medindo os níveis de IL-2, em nove lactentes com BA, encontraram uma correlação significativa entre a produção desta citocina nas vias aéreas superiores e inferiores. Van Schaik et al. ${ }^{15}$ também encontraram uma alta correlação $(r=0,972$, $\mathrm{p}=0,003$ ) entre os níveis de INF-g/IL-4 no ANF e aspirado traqueal de lactentes com sibilância induzida por infecção respiratória viral. Outros estudos também descreveram resultados similares, correlacionando os níveis de $\operatorname{IgE}$, exame citológico diferencial e subtipos de linfócitos e níveis de interleucinas, em relação à secreção nasofaríngea e lavado brônquico ou aspirado traqueal, nesse grupo de pacientes $5,6,17$. Com esses resultados e considerando a facilidade para obtenção desse tipo de amostra, o ANF tornou-se um dos métodos mais utilizados para se analisar a resposta inflamatória de pacientes com BA.

A predominância de neutrófilos na secreção nasofaríngea de todos os pacientes estudados, detectada neste estudo, sugere que este tipo de célula deve desempenhar um papel importante na BA. Este achado assemelha-se aos resultados já descritos em outros estudos, que incluem a análise de amostras de vias aéreas inferiores ${ }^{5-6}$. Os pacientes recrutados no presente estudo, provenientes de uma população de um país em desenvolvimento, apresentam as mesmas características de resposta celular nas vias aéreas daqueles de origem de países desenvolvidos. Com estes resultados, pode-se sugerir que a resposta neutrofílica das vias aéreas em crianças com BA poderia exercer um papel central na inflamação, contribuindo ativamente para o processo de obstrução brônquica. Além disto, este achado pode estar relacionado à resposta celular aguda da via aérea à infecção pelo VSR. A presença de outros tipos de vírus na etiologia da BA parece não refletir uma resposta inflamatória celular diferente. No presente estudo, nove pacientes apresentaram pesquisa de vírus respiratórios negativa no ANF. Provavelmente, estes casos podem estar associados a outros vírus, que não foram pesquisados neste estudo. Entretanto, as amostras de ANF desses pacientes apresentaram a mesma característica de resposta celular dos casos de infecção por VSR.

Por outro lado, a ausência de eosinófilos nas secreções nasofaríngeas avaliadas, somando-se às evidências da literatura ${ }^{5,6,18}$, coloca em dúvida a hipótese de que a BA possa ter um componente significativo de resposta eosinofílica, do tipo alérgica (Th2). Em doenças definitivamente alérgicas, pacientes apresentam eosinófilos em lavado nasal e em lavado broncoalveolar ${ }^{12,18}$. Ste- 
venson et al. ${ }^{19}$ demonstraram que crianças menores de cinco anos de idade, somente com sibilância e infecção respiratória viral, não apresentam eosinófilos no lavado broncoalveolar, ao contrário de crianças de maior idade com asma e atopia. Outra evidência, que também enfraquece essa hipótese, é a de que os episódios de sibilância da maioria dos lactentes tendem a se tornar menos freqüentes e menos graves com o passar dos anos, o que não aconteceria se houvesse um padrão atópico ${ }^{20}$.

Com essas informações, surge uma pergunta relevante em relação à origem da produção elevada de PCE nos estudos que analisaram tal proteína, em lactentes com BA ${ }^{2-}$ 4. Em um artigo de revisão, Gleich afirma que amostras originadas de lesões ricas em neutrófilos podem apresentar níveis elevados de $\mathrm{PCE}^{21}$. Essa afirmação origina-se de um estudo no qual foi evidenciada a presença de PCE em neutrófilos maduros, através de técnicas de imunofluorescência indireta e radioimunoensaio ${ }^{22}$. Portanto o conceito de que a PCE seja um marcador específico de inflamação associada ao eosinófilo deve ser reavaliado. Desta forma, e esta hipótese ainda não foi discutida na literatura, todos os estudos que encontraram níveis elevados de PCE em crianças com BA podem estar simplesmente refletindo o grau de resposta neutrofílica aguda encontrada nesses pacientes, pois nenhum estudo documentou uma presença mínima de eosinófilos nas vias aéreas de lactentes com sibilância.

Não foi incluído um grupo controle de lactentes normais neste estudo, devido à dificuldade de obtenção de amostra de ANF em crianças sem infecção respiratória. Estudos prévios que utilizaram lavado nasal em lactentes normais demonstraram que os neutrófilos não são as células predominantes neste local ${ }^{12}$. Assim, os achados do presente estudo parecem refletir a alteração da resposta celular das vias aéreas superiores de lactentes com infecção respiratória viral.

Os resultados desse estudo permitem demonstrar que a população de lactentes com BA, de um país em desenvolvimento, apresenta o mesmo tipo de perfil de resposta citológica encontrado em países desenvolvidos. Considerando esses resultados, o papel do eosinófilo na fisiopatogenia da BA deve ser melhor esclarecido. A resposta alérgica, em parte mediada por eosinófilos e encontrada em pacientes com asma, parece realmente não participar da fisiopatogenia da BA. A partir dos resultados do presente estudo e de estudos prévios, futuras pesquisas, analisando marcadores mais específicos de neutrófilos e eosinófilos, através de imunocitoquímica em secreção respiratória de lactentes com BA, poderiam esclarecer definitivamente a existência ou não da participação dos eosinófilos na fisiopatogenia da BA.

\section{Referências bibliográficas}

1. Everard ML. Acute bronchiolitis and pneumonia in infancy resulting from the respiratory syncytial virus. In: Taussig LM, Landau LI, editores. Pediatric Respiratory Medicine. $1^{\mathrm{a}}$ ed. Mosby; 1999. p. 580-95.
2. Garofalo R, Kimpen JLL, Welliver RC, Ogra PL. Eosinophil degranulation in the respiratory tract during naturally acquired respiratory syncytial virus infection. J Pediatr 1992;120:28-32.

3. Garofalo R, Dorris A, Ahlstedt S, Welliver RC. Peripheral blood eosinophil counts and eosinophil cationic protein content of respiratory secretions in bronchiolitis: relationship to severity of disease. Pediatr Allergy Immunol 1994;5:111-7.

4. Reijonen TM, Korppi M, Kleemola M, Savolainen K, Kuikka L, Monomen I, et al. Nasopharyngeal eosinophil cationic protein in bronchiolitis: relation to viral findings and subsequent wheezing. Pediatr Pulmonol 1997;24:35-41.

5. Everard ML, Swarbrick A, Wrightham M, McIntyre J, Dunkley $\mathrm{C}$, James PD, et al. Analysis of cells obtained by bronchial lavage of infants with respiratory syncytial virus infection. Arch Dis Child 1994;71:428-32.

6. Sheeran P, Jafri H, Carubelli C, Saavedra J, Johnson C, Krisher $\mathrm{K}$, et al. Elevated cytokine concentrations in the nasopharyngeal and tracheal secretions of children with respiratory syncytial virus disease. Pediatr Infect Dis J 1999;18:115-21.

7. Bourgeois ML, Goncalves M, Clainche LL, Benoist M, Fournet $\mathrm{J}$, Scheinmann P, et al. Bronchoalveolar cells in children $<3$ years old with severe recurrent wheezing. Chest 2002;122:791-7.

8. Pitrez PMC. Estudo da resposta inflamatória em lactentes com sibilância: análise de IL-10 e celularidade no aspirado nasofaríngeo [tese]. Porto Alegre (RS):Universidade Federal do Rio Grande do Sul; 2001.

9. The International Study of Asthma and Allergies in Childhood (ISAAC) Steering Committee. Worldwide variation in prevalence of symptoms of asthma, allergic rhinoconjunctivitis, and atopic eczema: ISSAC. Lancet 1998;351:1225-32.

10. Von Mutius E, Martinez FD, Fritzsch C, Nicolai T, Roell G, Thiemann H. Prevalence of asthma and atopy in two areas of west and east Germany. Am J Respir Crit Care Med 1994;149:358-64.

11. Noah TL, Henderson FW, Wortman IA, Devlin RB, Handy J, Koren HS, et al. Nasal cytokine production in viral acute upper respiratory infection of childhood. J Infect Dis 1995; 171:584-92.

12. Noah TL, Henderson FW, Henry MM, Peden DB, Devlin RB. Nasal lavage cytokines in normal, allergic, and asthmatic schoolage children. Am J Respir Crit Care 1995;152:1290-6.

13. Lim MC, Taylor RM, Naclerio RM. The histology of allergic rhinitis and its comparison to cellular changes in nasal lavage. Am J Respir Crit Care Med 1995;151:136-44.

14. Benson M, Strannegard I, Wennergren G, Strannegard O. Cytokines in nasal fluids from school children with seasonal allergic rhinitis. Pediatr Allergy Immunol 1997;8:143-9.

15. van Schaik SM, Welliver RC, Kimpen JLL. Novel pathways in the pathogenesis of respiratory syncytial virus disease. Pediatr Pulmonol 2000;30:131-8.

16. Joshi P, Kakakios A, Jayasekera J, Issacs D. A comparison of IL2 levels in nasopharyngeal and endotracheal aspirates of babies with respiratory syncytial viral bronchiolitis. J Allergy Clin Immunol 1998;102:618-20.

17. Everard ML, Fox G, Walls AF, Quint D, Fifield R, Walters C, et al. Tryptase and $\operatorname{IgE}$ concentrations in the respiratory tract of infants with acute bronchiolitis. Arch Dis Child 1995;72:64-9.

18. Marguet C, Dean TP, Warner JO. Soluble intercellular adhesion molecule-1 (sICAM-1) and interferon-gamma in bronchoalveolar lavage fluid from children with airway diseases. Am J Respir Crit Care Med 2000;162:1016-22.

19. Stevenson EC, Turner G, Heany LG, Schock BC, Taylor R, Gallagher T, et al. Bronchoalveolar lavage findings suggest two different forms of childhood asthma. Clin Exp Allergy 1997;27:1027-35.

20. Henderson FW, Collier AM, Clyde WA Jr, Denny FW. Respiratory syncytial virus infections, reinfections and immunity - A prospective, longitudinal study in young children. N Engl J Med 1979;300:530-4. 
21. Gleich GJ. Mechanisms of eosinophil-associated inflammation. J Allergy Clin Immunol 2000;105:651-63.

22. Sur S, Glitz DG, Kita H, Kujawa SM, Peterson EA, Weiler DA, et al.Localization of eosinophil-derived neurotoxin and eosinophil cationic protein in neutrophilic leukocytes. J Leukoc Biol 1998;63:715-22.
Endereço para correspondência:

Dr. Paulo M.C. Pitrez

Av. Cel. Lucas de Oliveira, 2213/303

CEP 90460-001 - Porto Alegre - RS

Tel./Fax: (51) 3384.5104

E-mail:pmpitrez@pucrs.br 